\title{
Expression of Human Epidermal Growth Factor Receptor 2 in Meningiomas
}

\begin{abstract}
Background: Meningiomas consist of $15 \%-30 \%$ of the primary intracranial tumors, and high-grade meningiomas have a higher recurrence after surgery. The human epidermal growth factor receptor 2 (HER2) status is important in the medical management of patients with various human cancers. This study aimed to evaluate HER2 expression in meningiomas and the correlation between this expression and age, gender, and grade. Materials and Methods: In a descriptive-analytic study, immunohistochemistry (IHC) with HER2 marker was done on confirmed cases of meningioma which were referred to the pathology laboratory from 2008 to 2015 . The primary antihuman antibody against c-erbB-2 oncoprotein (DAKO Diagnostics) was used for IHC. Results: Of 117 patients, $68.4 \%$ were males. The mean age of the patients was 53.6 years. Grades I, II, and III tumors were $90.6 \%, 8.5 \%$, and $0.9 \%$ of cases, respectively. Totally, $76(65 \%)$ of patients were HER2 positive, with only $7.7 \%$ of highly expressed HER2. There was no significant correlation between the mean age $(P=0.672)$, age group $(P=0.256)$, sex $(P=0.574)$, and grade $(P=0.093)$ and HER2 expression status. Conclusions: We did not find a statistically significant correlation between age, sex, or grade and HER2 status; however, further studies with a higher number of Grades II and III meningiomas and using the fluorescent in situ hybridization in equivocal cases may be of benefit in this way.
\end{abstract}

Keywords: Human epidermal growth factor receptor 2, immunohistochemistry, meningioma

\section{Introduction}

Meningiomas include between $15 \%$ and $30 \%$ of the primary intracranial tumors with an annual incidence of $5 / 100,000 .^{[1,2]}$ These tumors develop more in middle and late adulthood. ${ }^{[1]}$ Meningiomas were graded into three groups (Grade I: benign), (Grade II: atypical), and (Grade III: anaplastic or malignant). ${ }^{[3]}$ Most meningiomas are benign tumors, but up to $15 \%$ are atypical, and $2 \%$ malignant according to the World Health Organization histological criteria reported in 2016. ${ }^{[2]}$ Meningiomas more often afflict women than men and are rare but often aggressive in children. ${ }^{[4,5]}$ Despite the molecular mechanisms of meningioma having been described, the curative effects of current treatments for invasive and malignant meningiomas have been unsatisfactory. ${ }^{[6]}$ Tumor recurrence was observed in 7\%-20\% of Grade I, $29 \%-40 \%$ of Grade II, and $50 \%-78 \%$ of Grade III meningiomas, following surgery. Due to high tumor recurrence

This is an open access journal, and articles are distributed under the terms of the Creative Commons Attribution-NonCommercial-ShareAlike 4.0 License, which allows others to remix, tweak, and build upon the work non-commercially, as long as appropriate credit is given and the new creations are licensed under the identical terms.

For reprints contact: WKHLRPMedknow_reprints@wolterskluwer.com in Grade II/III meningiomas, additional treatment protocols with targeted therapy may be required with the available chemotherapeutic drugs. ${ }^{[1,3]}$ The human epidermal growth factor receptor 2 (HER2), also known as ErbB2, is a $185-\mathrm{kD}$ transmembrane glycoprotein with tyrosine kinase activity expressed in meningiomas and various other tumors. ${ }^{[7]}$ HER2 status is important in the medical management of patients with various human cancers ${ }^{[8]}$ and can be a therapeutic target with monoclonal antibodies for meningiomas that interact with HER2 receptors, ${ }^{[1,9]}$ but the prognostic value of this receptor protein in meningiomas is ambiguous. ${ }^{[10,11]}$ This study aimed to evaluate the HER2 expression in meningiomas and the correlation between this expression and age, gender, and grade.

\section{Materials and Methods}

\section{Specimen selection}

In this descriptive-analytic study, paraffin blocks were checked in patients with meningiomas admitted to the pathology laboratory of Imam Reza Hospital,

How to cite this article: Ramezani M, Firoozabadi $\mathrm{H}$, Rezaei M, Khazaei S, Sadeghi M. Expression of human epidermal growth factor receptor 2 in meningiomas. Indian J Med Paediatr Oncol 2020;41:15-8.

\section{Mazaher Ramezani', Hanieh \\ Firoozabadi², Mansour Rezaei ${ }^{3}$, Sedigheh Khazaei ${ }^{1}$, Masoud Sadeghi ${ }^{4}$}

${ }^{I}$ Molecular Pathology Research Center, Imam Reza Hospital, Kermanshah University of Medical Sciences, Kermanshah, Iran, ${ }^{2}$ Students Research Committee, Kermanshah University of Medical Sciences, Kermanshah, Iran, ${ }^{3}$ Department of Biostatistics, Fertility and Infertility Research Center, Kermanshah University of Medical Sciences, Kermanshah, Iran, ${ }^{4}$ Medical Biology Research Center, Kermanshah University of Medical Sciences, Kermanshah, Iran

Submitted: 11-Jan-2019 Revised: 14-Oct-2019 Accepted: 10-Nov-2019 Published: 24-Apr-2020

Address for correspondence: Mr. Masoud Sadeghi, Medical Biology Research Center, Kermanshah University of Medical Sciences, Kermanshah, Iran. E-mail: sadeghi_mbrc@yahoo. com

Access this article online

Website: www.ijmpo.org

DOI: 10.4103/ijmpo.ijmpo_10_19 Quick Response Code:

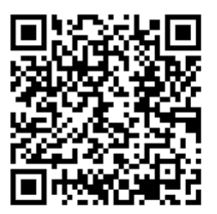


Kermanshah, Iran, from 2008 to 2015. After referring to the computer file and the offices in the pathology laboratory, the samples were selected to reach a sufficient sample size (117 samples).

\section{Immunohistochemistry}

At first, hematoxylin and eosin ( $\mathrm{H}$ and $\mathrm{E})$-stained slides were collected from each sample from the archives and then the paraffin blocks were prepared by $4-\mu$ sections for the $\mathrm{H}$ and $\mathrm{E}$ routine staining and immunohistochemistry (IHC) staining with the HER2 marker. The tissue sections were reexamined by the pathologist and the diagnosis of meningioma was confirmed. Then, IHC specimens were examined. Primary antihuman antibody against c-erbB-2 oncoprotein (DAKO Diagnostics, Polyclonal Rabbit Antihuman c-erbB-2 Oncoprotein, Code A0485) was used for the IHC. According to the pattern of staining, the specimen was marked as IHC0 (less than $10 \%$ of the tumor cells were stained; negative), $\mathrm{IHC1}+$ (more than $10 \%$ of the tumor cells were stained and the membrane of the cells was incomplete and poorly stained, negative), $\mathrm{IHC} 2+$ (more than $10 \%$ of the tumor cells were stained and the cell membrane was full but weak-to-medium staining, ambiguous, or duplex), and IHC3+ (more than $10 \%$ of the tumor cells were stained and the cell membrane was full and strong staining, positive). Then, the results were recorded in the data collection form. We considered score 0 and $1+$ as negative, while those with score $2+$ and $3+$ considered as positive. A ductal carcinoma of the breast (in which the intense and high percentages of cells were stained for the HER2 marker) was used as a positive control of IHC and a normal breast sample as a negative control. Figure 1 demonstrates IHC staining patterns in meningiomas.

\section{Statistical analysis}

The data were analyzed by SPSS version 22 (IBM Corp., Armonk, NY, USA) and by binary logistic regression (odds ratio $[\mathrm{OR}]$ and $95 \%$ confidence interval $[\mathrm{CI}]) . P<0.05$ was considered to be statistically significant.

\section{Ethical approval}

This study was approved by the Ethics Committee of Kermanshah University of Medical Sciences, Kermanshah, Iran. The names of the patients remained confidential, and no additional costs were imposed on patients.

\section{Results}

The mean age of patients was 53.6 years (range, $1-88$ years); $68.4 \%$ were males and $59.8 \%$ had age $>50$ years [Table 1 ]. Of 117 patients, 106 patients (90.6\%) had Grade I, $10(8.5 \%)$ had Grade II, and $1(0.9 \%)$ had Grade III. With regard to HER2 expression, 4 (3.4\%) had IHC0, 37 (31.6\%) IHC1+, 67 (57.3\%) IHC2+, and 9 (7.7\%) IHC3+. Totally, $76(65 \%)$ patients were HER2 positivity and $41(35 \%)$ were negativity.

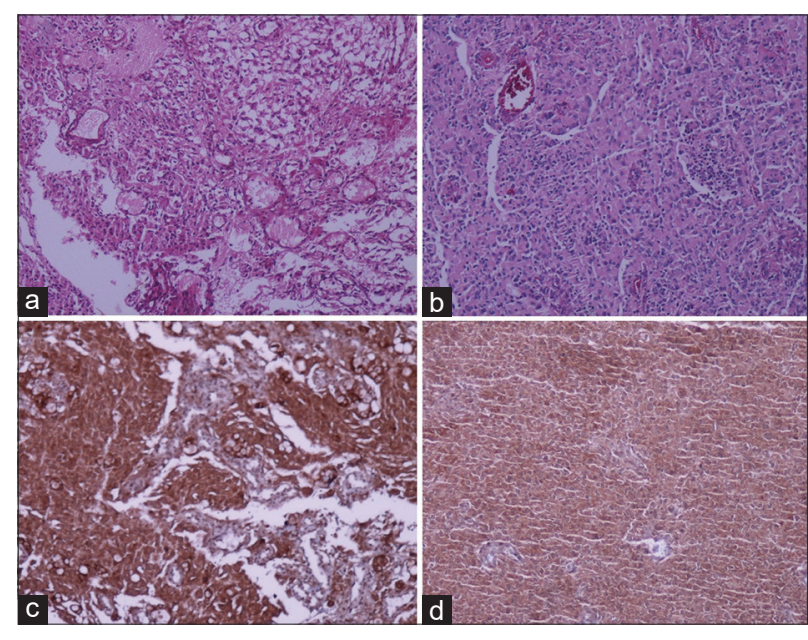

Figure 1: Meningioma: (a) Grade I, H and E, $\times 100$. (b) Grade II, H and E, $\times 100$. (c) HER2 positivity $3+$, immunohistochemistry; $\times 100$ (case A). (d) HER2 positivity $2+$, immunohistochemistry; $\times 100$ (case B). HER2 - Human epidermal growth factor receptor 2

A comparison between three variables with HER2 expression status by binary logistic regression is shown in Table 2. The results showed that there was no significant correlation between the mean age $(\mathrm{OR}=1.012 ; 95 \% \mathrm{CI}$ : $0.967,1.060 ; P=0.605)$, age group $(\mathrm{OR}=0.552 ; 95 \% \mathrm{CI}$ : $0.158,1.935 ; P=0.353)$, sex $(\mathrm{OR}=1.123 ; 95 \% \mathrm{CI}: 0.482$, $2.615 ; P=0.788)$, and grade $(\mathrm{OR}=0.655 ; 95 \% \mathrm{CI}: 0.179$, 2.399; $P=0.523)$ with HER2 expression status.

\section{Discussion}

Meningiomas are caused by arachnoid cells, and typically, these tumors are slow-growing lesions, but the recurrence followed by surgical treatment is a problem with which they are. ${ }^{[1]}$ Understanding the invasive molecular mechanism may help design appropriate treatments and increase survival rates. ${ }^{[12]}$ Due to the significant recurrence rate, including Grades I and II, treatment for meningiomas requires modalities such as existing drugs. ${ }^{[1]}$ Meanwhile, in all cases of meningioma, there is no possibility of complete resection of the lesion, and the remainder of the tumor may not be controlled by radiotherapy. Therefore, targeted molecular therapies for the effects on meningiomas can be very beneficial, especially if you need to reduce neurological interventions. ${ }^{[13,14]}$ In this regard, the HER2 family is noteworthy that they are effective tyrosine kinase receptors in a tumorigenic activity. ${ }^{[13]}$ These receptors play important roles in the direction of the cell signal involved in cell growth. ${ }^{[15]}$ The family of tyrosine kinase growth factor receptors, in addition to HER2, also contains HER1, HER3, and HER4. ${ }^{[15,16]}$ Excessive expression of the HER2 gene has been found in many different types of human malignancies, including the breast, lung, ovary, stomach, pancreas, prostate, and colorectal, and cancers of the female genital tract, with a poor prognosis in at least a few of them. ${ }^{[1,16,17]}$ Previous studies have shown a different 


\begin{tabular}{lc}
\hline \multicolumn{2}{c}{ Table 1: The baseline characteristics of the patients } \\
\hline Variable & Value \\
\hline Age (years) & \\
Mean \pm SD & $53.6 \pm 13.4$ \\
Range & $1-88$ \\
$\leq 50 />50(\%)$ & $47(40.2) / 70(59.8)$ \\
Sex (\%) & \\
Male & $80(68.4)$ \\
Female & $37(31.6)$ \\
Grade (\%) & \\
I & $106(90.6)$ \\
II & $10(8.5)$ \\
III & $1(0.9)$ \\
HER2 expression (\%) & \\
0 & $4(3.4)$ \\
$1+$ & $37(31.6)$ \\
$2+$ & $67(57.3)$ \\
$3+$ & $9(7.7)$ \\
HER2 status (\%) & \\
Positive & $76(65)$ \\
Negative & $41(35)$ \\
\hline
\end{tabular}

SD - Standard deviation; HER2 - Human epidermal growth factor receptor 2

Table 2: The correlation between the variables with human epidermal growth factor receptor 2 expression status (human epidermal growth factor receptor 2 positive and human epidermal growth factor receptor 2 negative) based on the binary logistic regression

\begin{tabular}{lccr}
\hline Variable & $\boldsymbol{P}$ & OR & \multicolumn{1}{c}{$\mathbf{9 5 \%}$ CI } \\
\hline Age (years) & & & \\
$\quad$ Mean \pm SD & 0.605 & 1.012 & $0.967,1.060$ \\
$\quad \leq 50$ versus $>50$ & 0.353 & 0.552 & $0.158,1.935$ \\
$\begin{array}{l}\text { Sex } \\
\quad \text { Male versus female }\end{array}$ & 0.788 & 1.123 & $0.482,2.615$ \\
$\quad \begin{array}{l}\text { Grade } \\
\quad \text { I and II versus III }\end{array}$ & 0.523 & 0.655 & $0.179,2.399$ \\
\hline OR - Odds ratio; CI - Confidence interval; SD - Standard deviation
\end{tabular}

level of HER2 expression in various types of brain tumors. ${ }^{[1]}$ Some studies have reported the high expression of this receptor in medulloblastoma and its association with poor prognosis in these tumors. ${ }^{[1,16]}$ HER2 protein has also been reported in the pituitary adenoma and vestibular schwannoma ${ }^{[1]}$ In a study with work on human invasive specimens, expression and excessive activity of HER2 and HER3 were shown. ${ }^{[14]}$ In fact, only a few studies have done about the association between meningiomas and HER2 expression, and the results are different. ${ }^{[1,8,12,17,18]}$

Wang et al. ${ }^{[19]}$ using IHC method showed that the expression of HER2 in benign meningiomas (no recurrence/initial), the benign recurrence group, the atypical group, and malignant group reported as follows: $35 \%, 30 \%, 15 \%$, and $50 \%$. It was also suggested in this study that higher tumor grade was associated with a higher expression of HER2 expression, and the HER2 gene amplification was reported in 7 of 26 samples (26.9\%) of HER2 2+ meningiomas. In a study by Anderson et al., the expression of the HER2 family in relation to various parameters in 44 glioma and 26 meningioma samples was analyzed using real-time polymerase chain reaction; the expressions of HER1, HER2, and HER4 in the majority of meningiomas were observed. However, HER 3 was found only in one of the samples. In addition, the immunohistochemical method showed a high expression of HER2 in meningiomas. ${ }^{[16]}$ In a study by Mahzouni and Movahedipour using immunohistochemical methods and in a retrospective study, ${ }^{[1]} 31$ of 72 samples of meningiomas (43\%) were HER2 positivity $(55 \%$ of Grades II or III and $38.5 \%$ of Grade I samples). Although Grade II meningiomas showed a higher HER2 protein immunoreactivity, this difference was not statistically significant. In this study, HER2 expression was seen in $39 \%$ male and $44.9 \%$ female samples, but there was no statistically significant difference between the two genders. In a 2008 study by Durand et al., on human meningiomas, ${ }^{[20]}$ the association of the expression of HER2 gene with gradient and histologic grade of the tumor was investigated that the levels of mRNA of this gene did not correlate with histological grade. One study ${ }^{[7]}$ on 100 samples of meningioma (including 80 samples of Grade I, 18 of Grade II, and 2 of Grade III) investigated the association between HER2 expression and sex, location, grade, and subtypes of meningiomas. According to the results of this study, HER2 positivity was seen in $73 \%$ of the samples $(75 \%$ of Grade I, $72.2 \%$ of Grade II, and $0 \%$ of Grade III samples). There was no significant association between HER2 expression and the mentioned factors. Another study ${ }^{[21]}$ checked the expression of HER2 in 60 meningioma samples (48 samples with Grade I and 12 samples with Grades II or III) using IHC and the relationship between the expression of HER 2 and sex, age, tumor grade, and recurrence or regrowth. HER2 positivity was seen in $88.3 \%$ of the samples $(31.7 \%$ - weak, $38.3 \%$ - moderate, and $18.3 \%$ - strong). There was no statistically significant difference between sex, age, tumor grade, and recurrence and HER2 expression. Of 186 human meningiomas of all malignancy grades that 163 of these were in tissue microarrays, about $48 \%$ and $11 \%$ were HER2 positivity with antibodies against the extracellular domain and against the activated receptor, respectively, without gene amplification. ${ }^{[8]}$

\section{Conclusions}

In general, the high expression of HER2 in this study was found in $7.7 \%$ of meningiomas (9 of 117 samples). However, there was no significant difference between the expression of HER2 and sex, age, and tumor grade. Further studies with a higher number of Grade II and III meningiomas and using the fluorescent in situ hybridization in equivocal cases may be of benefit in this way. 


\section{Acknowledgment}

The authors gratefully acknowledge the Research Council of Kermanshah University of Medical Sciences (Grant Number: 95355) for the financial support. The authors would like to thank the Clinical Research Development Center of Imam Reza Hospital for consulting services. This work was performed in partial fulfillment of the requirements for the degree of General Practitioner by Hanieh Firoozabadi at Faculty of Medicine, Kermanshah University of Medical Sciences, Kermanshah, Iran.

\section{Financial support and sponsorship}

Nil.

\section{Conflicts of interest}

There are no conflicts of interest.

\section{References}

1. Mahzouni P, Movahedipour M. An immunohistochemical study of HER2 expression in meningioma and its correlation with tumor grade. Pathol Res Pract 2012;208:221-4.

2. Apra C, Peyre M, Kalamarides M. Current treatment options for meningioma. Expert Rev Neurother 2018;18:241-9.

3. Perry A, Louis DN, Scheithauer BW, Budka H, Deimling VA. Meningiomas. In: Louis DN, Ohgaki H, Wiestler OD, Cavenee WK, editors. World Health Organization Classification of the Central Nervous System. Lyon: IARC; 2007. p. 164-72.

4. Ostrom QT, Gittleman H, Farah P, Ondracek A, Chen Y, Wolinsky Y, et al. CBTRUS statistical report: Primary brain and central nervous system tumors diagnosed in the United States in 2006-2010. Neuro Oncol 2013;15 Suppl 2:ii1-56.

5. Thuijs NB, Uitdehaag BM, Van Ouwerkerk WJ, van der Valk P, Vandertop WP, Peerdeman SM. Pediatric meningiomas in the Netherlands 1974-2010: A descriptive epidemiological case study. Childs Nerv Syst 2012;28:1009-15.

6. Wang S, Liu X, Wang W, Tu Y, Wang C, Mei J, et al. The effects of silencing the her2 gene on proliferation and angiogenesis of meningioma cells in vivo and in vitro. Ann Clin Lab Sci 2018;48:580-6.

7. Telugu RB, Chowhan AK, Rukmangadha N, Patnayak R, Phaneendra BV, Prasad BC, et al. Human epidermal growth factor receptor $2 /$ neu protein expression in meningiomas: An immunohistochemical study. J Neurosci Rural Pract 2016;7:526-31.

8. Arnli MB, Winther TL, Lydersen S, Torp SH. Prognostic value of ErbB2/HER2 in human meningiomas. PLoS One 2018; 13:e0205846.

9. Olsen RJ, Lydiatt WM, Koepsell SA, Lydiatt D, Johansson SL, Naumann S, et al. C-erb-B2 (HER2/neu) expression in synovial sarcoma of the head and neck. Head Neck 2005;27:883-92.

10. Potti A, Panwalkar A, Langness E, Sholes K, Tendulkar K, Chittajalu S, et al. Role of her-2/neu overexpression and clinical features at presentation as predictive factors in meningiomas. Am J Clin Oncol 2004;27:452-6.

11. Abdelzaher E, El-Gendi SM, Yehya A, Gowil AG. Recurrence of benign meningiomas: predictive value of proliferative index, BCL2, p53, hormonal receptors and HER2 expression. Br J Neurosurg 2011;25:707-13.

12. Wang W, Tu Y, Wang S, Xu S, Xu L, Xiong Y, et al. Role of HER-2 activity in the regulation of malignant meningioma cell proliferation and motility. Mol Med Rep 2015;12:3575-82.

13. Wickremesekera A, Hovens CM, Kaye AH. Expression of ErbB-1 and ErbB-2 in meningioma. J Clin Neurosci 2010;17:1155-8.

14. Ammoun S, Schmid MC, Ristic N, Zhou L, Hilton D, Ercolano E, et al. The role of insulin-like growth factors signaling in merlin-deficient human schwannomas. Glia 2012;60:1721-33.

15. Loussouarn D, Brunon J, Avet-Loiseau H, Campone M, Mosnier JF. Prognostic value of HER2 expression in meningiomas: an immunohistochemical and fluorescence in situ hybridization study. Hum Pathol 2006;37:415-21.

16. Andersson U, Guo D, Malmer B, Bergenheim AT, Brännström $\mathrm{T}$, Hedman $\mathrm{H}$, et al. Epidermal growth factor receptor family (EGFR, ErbB2-4) in gliomas and meningiomas. Acta Neuropathol 2004;108:135-42.

17. Waage IS, Vreim I, Torp SH. C-erbB2/HER2 in human gliomas, medulloblastomas, and meningiomas: A minireview. Int J Surg Pathol 2013;21:573-82.

18. Laurendeau I, Ferrer M, Garrido D, D'Haene N, Ciavarelli P, Basso A, et al. Gene expression profiling of ErbB receptors and ligands in human meningiomas. Cancer Invest 2009;27:691-8.

19. Wang CL, Mei JH, Wang SS, Xu S, Xu LL, Xiong YF. Expression of HER2/neu in meningiomas: An immunohistochemistry and fluorescence in situ hybridization study. Zhonghua Bing Li Xue Za Zhi 2010;39:156-60.

20. Durand A, Champier J, Jouvet A, Labrousse F, Honnorat J, Guyotat $\mathrm{J}$, et al. Expression of c-Myc, neurofibromatosis Type 2, somatostatin receptor 2 and erb-B2 in human meningiomas: relation to grades or histotypes. Clin Neuropathol 2008;27:334-45.

21. Ongaratti BR, Silva CB, Trott G, Haag T, Leães CG, Ferreira NP, et al. Expression of merlin, NDRG2, ERBB2, and c-MYC in meningiomas: relationship with tumor grade and recurrence. Braz J Med Biol Res 2016;49:e5125. 